\title{
Complementary and Alternative Medicine (CAM) Utilization Rates in New Mexico: Recommendations for Marketing and Mentorship between Professionals and Students
}

\section{Introduction}

In the United States, more than two-thirds of the population has used some form of what is commonly known as Complementary and Alternative Medicine (CAM) [1]. CAM represents a variety of "healing philosophies, approaches and therapies that exist largely outside the main frame of the conventional treatment" [2]. Complementary refers to treatments that are used along with western medicine, whereas alternative refers to therapies that are used in place of conventional medicine [2,3]. Both complementary and alternative therapies focus on the entire person by treating a person's physical, emotional, mental, and spiritual health [4]. Some of these therapies include "mind-body medicine" (such as meditation, acupuncture, and yoga), "manipulative practices" (such as massage therapy and spinal manipulation), and "natural products" (such as herbs and dietary supplements) [4]. Efforts to bridge CAM and conventional medicine are called integrative medicine and work to combine best practices in both CAM and conventional medicine [4]. For continuity of variables authors use the term CAM rather than "integrative medicine" to align services studied by the Centers for Disease Control and Prevention (CDC).

This paper aims to engage in the process of closing those gaps by discussing specific areas related to CAM. First, to provide a national context of CAM, authors discuss industry size and ethnicity based utilization trends in the US. Second, to survey CAM usage levels across ethnic groups in the state of New Mexico. Third, to explore potential engagement strategies for underserved communities in New Mexico through marketing, continuing education, and mentorship. Lastly, to discuss contextual issues such as cultural appropriation and the ethical questions involved in integrating these therapies into the menu of mainstream healthcare options. The literature is consistent in its declaration that CAM usage varies by ethnicity [5-7, but whether that variability is replicated in New Mexico or not requires further investigation.

Are CAM Utilization Rates that Vary by Ethnicity Connected to Ethnic Background in a Meaningful Way?

While a large percentage of the population has some exposure to CAM, there remain substantial gaps in our understanding of utilization trends across diverse ethnic and racial groups. This article discusses findings from the New Landscapes of a MajorityMinority State: Politics, Economy, Health, and Well-Being in New Mexico (NLMMS) Survey. Based on these findings authors discuss viable strategies for engaging underserved populations within the context of New Mexico healthcare. This paper distinguishes

Conceptual Paper
Volume 9 Issue 1 - 2017
Anna Dinallo*, Gary Allison and Melina
Juarez
Integrative Health Education LLC, University of New Mexico,
USA
*Corresponding author: Anna Dinallo, Integrative Health
Education LLC, University of New Mexico, Fellow Center for
Health Policy, USA, Tel: 505-280-4670; Email:
ana.dinallo@ocom.edu
Received: October 06, 2017 | Published: October 17, 2017

between mainstream forms of CAM and less commonly evaluated ones. For the purposes of this article, the authors focus on CAM therapies that have shown strong evidence of effectiveness and a positive risk to benefit analysis [8].

\section{Complementary and Alternative Medicine (CAM) Types and Usage}

It is estimated that Americans are spending $\$ 14.7$ billion on complementary practitioners and $\$ 12.8$ billion on natural product supplements each year [9]. While CAM is generally referred to as, "healthcare systems, practices and products not currently considered part of conventional medicine" [1], CAM represents a large constellation of diverse therapies that vary significantly in cost, usage, and origins. Some practices within CAM include: yoga, meditation, mindfulness, acupuncture, curanderismo, shamanism, reiki, massage, and herbal nutrition. Some examples of mainstream CAM therapies include yoga (e.g. hatha), acupuncture, and chiropractic.

In 2009, adults in the U.S. spent about $\$ 22$ billion dollars out of pocket for self-care costs. These costs included CAM products, classes, and materials. An additional $\$ 14.8$ billion were spent on dietary supplements; $\$ 4.1$ billion on yoga, tai chi, and qigong classes; $\$ 2.9$ billion on homeopathic medicine; and $\$ 0.2$ billion on relaxation techniques [10]. By 2012, these spending numbers fluctuated. The 2012 National Health Interview Survey (NHIS) found that adults in the U.S. spent approximately $\$ 14.1$ billion each year on CAM practitioner visits and $\$ 12$ billion on CAM dietary supplements. Although CAM spending for children is only a fraction of that for adults, their expenditures on CAM is also a multimillion-dollar industry. Dietary supplement expenditures for 
children were approximately $\$ 0.8$ billion while CAM practitioner expenditures stood at $\$ 0.6$ billion for 2012 [11], this lack of knowledge often can stem from bartering practices.

\section{Usage across Ethnic Groups}

Bausell et al. [6] \& Ni et al. [12] suggest that Whites access CAM services at higher rates than other ethnic groups. Some differences across groups include the following: Asians are higher users of acupuncture and Oriental medicine, Hispanics of dietary supplements, home remedies, and curanderos (folk medicine practitioners), and Whites of chiropractic massage, diet, and psycho-spirituality [7]. In the United States the 10 most frequently used CAM therapies in 2004 were the following; use of prayer specifically for one's own health $(43.0 \%)$, prayer in a community for individual's health (24.4\%), natural health products (18.9\%), deep breathing exercises (11.6\%), participation in a prayer group for one's own health (9.6\%), meditation (7.6\%), chiropractic care $(7.5 \%)$, yoga (5.1\%), massage $(5.0 \%)$, and diet-based therapies (3.5\%), (note above list uses Barnes order of findings and terminology for clarity) (Barnes et al., 2004). While CAM is most often used to treat back pain or back problems, head or chest colds, neck pain or neck problems, joint pain or stiffness, it is also used to treat emotional issues such as anxiety or depression or spiritual issues such as "mal ojo" (negative eye) [10].

\section{Evidence Based Outcomes}

Because many CAM therapies have been included under a large blanket definition that encompasses treatment outside of conventional medicine, it is important to note that not all therapies have evidence-based outcomes. Some forms of CAM, such as shamanism and folk prayer, use spiritual healing techniques. Western scientific instruments have yet to measure "god" and spiritual systems of health, so it is inconclusive if these modalities have impact beyond a placebo effect. Thus scientists can use qualitative techniques and psychological metrics to report subjective outcomes. Self-reporting Likert scales and subjective pain relief for complex symptoms are often used in conventional medical settings $[13,14]$. It is also important to note that CAM oversight and regulation is much less systematized than is conventional healthcare. Prescribed methods, administration, and applications can vary greatly from one user to the next and one caregiver to the next. Some forms of CAM have been shown to have little or no evidence of effectiveness [8]. On the other hand, there is strong evidence that some forms of CAMs are very effective. Some of the more effective technique/ailment combinations include but are not limited to: acupuncture for nausea, herbalism for depression, chiropractic for back pain, and aromatherapy for stress relief [8], as well as yoga and meditation for relaxation [15]. Despite a need for research across CAM modalities, individuals who display"Openness to new experience," spirituality and mood awareness are more likely to use CAM [16]. Cross discipline research has demonstrated that native populations and groups of color prefer health modalities that consider spiritual heath. This is especially true for woman of color, including Hispanic women, particularly Mexican Americans and Puerto Ricans, and African American women [17].
Healthcare decisions are influenced by cultural knowledge, beliefs and experience. When exploring reasons why diverse ethics groups seek out CAM it is important to note, people rarely make healthcare decisions without consideration for cultural knowledge, beliefs, and experience. According to Roberson (1987), mode of use, substances used, and beliefs associated with usage are all determined with respect to specific cultural contexts. Underserved groups often view the widely accepted healthcare system with skepticism. Factors associated with this negative perception include but are not limited to: personal experiences with a one size fits all approach, history of abuse and experimentation, prohibitive costs, transportation issues, and the bureaucratic nature of the healthcare visits. The prohibitive costs of conventional healthcare continue to play a large role in discussions about whether access to healthcare is a right or a privilege. Those with insurance have been dealing with increases in premiums, deductibles, and copays. Those without insurance are forgoing preventative healthcare measures, and when they face dire situations are incurring unmanageable amounts of debt. Transportation issues represent a significant barrier to accessing healthcare services. Per Syed, et al. [18], transportation issues most often impact healthcare access when they result in rescheduled and/or missed appointments, delays in treatment, and the delay or lack of medication utilization. Regarding bureaucracy, healthcare services providers regularly face the competing interests of cost-efficiency and production against "person-centered care" [19]. Patients often get the short end of the stick when they are caught amid this balancing act, and leave feeling with the idea that healthcare providers care about the business of health, but not the health of the patient due to the for profit and corporate model of health in the United States.

\section{National Data on CAM}

National data on CAM usage is tracked by the Centers for Disease Control and Prevention (CDC) through the National Health Interview Survey (NHIS) conducted every five years. The NHIS includes data for both children and adults. Over 33\% of adult respondents of the NHIS said they used some form of CAM. Researchers asked respondents about their usage in the following categories: supplements, deep-breathing exercises, yoga, tai chi, qi gong, chiropractic, meditation, massage therapy, acupuncture, and energy healing therapy (CDC 2012). Of these, supplements, deep breathing, and yoga were the most widely used. The use of yoga has doubled in the past decade, with respondents reporting practicing yoga increasing from $5.8 \%$ in 2002 to over $10 \%$ by 2012. Chiropractor usage was the fourth most widely used trending from $7.5 \%$ in $2002,8.6 \%$ in 2007, and $8.4 \%$ in 2012 [11].

Clarke et al. [11] also found utilization differences by sociodemographic characteristics. CAM utilization was seen across all age groups. However, those aged 45-64 had the highest utilization rates $(36.8 \%)$ compared to other ages. In terms of race and ethnicity, Hispanics and Blacks had the lowest rates of CAM utilization compared to whites across the three survey years. Table 1 illustrates these trends. CAM utilization rates were also highest among the most educated with college degrees or higher $(42.6 \%)$, those with private insurance (38\%), and women (37.4\%). 
Table 1: National Health Interview Survey 2002, 2007, 2012 CAM Utilization by Race \& Ethnicity.

\begin{tabular}{|c|c|c|c|c|c|c|}
\hline \multirow[b]{2}{*}{ Race/Ethnicity } & \multicolumn{2}{|c|}{2002} & \multicolumn{2}{|c|}{2007} & \multicolumn{2}{|c|}{2012} \\
\hline & N (In Thousands) & Adjusted \% & N (In Thousands) & Adjusted \% & N (In Thousands) & Adjusted \% \\
\hline Hispanic & 5,626 & 26.4 & 6,162 & 21.6 & 7,525 & 22.0 \\
\hline White & 50,219 & 34.4 & 59,814 & 40.2 & 57,008 & 37.9 \\
\hline Blacks & 5,181 & 22.9 & 5,688 & 22.9 & 4,957 & 19.3 \\
\hline *Other & 4,142 & 41.5 & 5,368 & 39.6 & 5,946 & 37.3 \\
\hline Total & 65,168 & & 77,032 & & 75,436 & \\
\hline
\end{tabular}

There are interesting patterns that emerge when compare various ethnic patterns. For example White of higher socioeconomic backgrounds heavily utilizes Whites of chiropractic massage, diet, and psycho-spirituality and Latino populations use curanderos/sobadores. Interestingly, national data on CAM utilization also exists for one underserved group as well: farm workers. The Department of Labor's National Agricultural Workers Survey (NAWS) conducted since 1989 includes two CAM provider options in their healthcare services battery. They ask: The last time you used the health care provider, where did you go (what kind of place was it)? Answer categories include: community health centers, private medical doctors/private clinic, Curandero/sobador, hospital, emergency room, migrant health center, chiropractor or naturopath's office, and dentist $[20,21]$.

Community health centers, private doctors and clinics, as well as dentists were the most frequented sources of care from 2007-2012. Neither curanderos/sobadores or chiropractor or neuropathic offices received anything above a 1\% usage rate for any year in the same time frame. This means that although national data suggests the overall population engages in some forms of CAM, this group (farmworkers) does not engage at the same rates. This is important to note for our study as farmworkers represent a highly underserved groups that intersects class and race and ethnic lines.

\section{New Mexico Diverse Context}

New Mexico is the site of our case study given its status as a majority-minority state (46.4\% Hispanic, $8.8 \%$ Native American) and its complex cultural and ethnic diversity. Some statistics from the New Mexico Department of Health (2016) exemplify this:

a. 23 federally-recognized tribes.

b. 36 out of $100 \mathrm{New}$ Mexicans speak a language other than English.

c. $10 \%$ of population is made up of immigrants.

d. 3\% LGBTQ (one of the highest in the country) [22].

New Mexico is a majority-minority state where nearly half of the population identifies as Hispanic [23]. In a broader context, the Hispanic represents a pan-ethnic term that implies greater "assimilation into mainstream US society" and identity [24]. Within New Mexico, the term Hispanic often indicates ancestry from Spain and illuminates the historical and racial tension between Mexican and Native groups [25]. Yet, due to periods of both Spanish and Mexican occupancy that house various waves of immigration patterns from Mexico prior to statehood in 1912 [25], the term Hispanic in a NM context may also represent voices from Mexican-American backgrounds. In the study, authors use the term Hispanic but acknowledge the issue of referencing a vague ethnic category, as the term represents diverse linguistic, racial, ethnic, historical, and geographic backgrounds of many groups of people.

\section{Methods}

Data for our case study comes from the Robert Wood Johnson Foundation Center for Health Policy at the University of New Mexico's survey "The New Landscapes of a Majority-Minority State: Politics, Economy, Health, and Well-Being in New Mexico" (NLMMS). The survey only includes residents of New Mexico aged 18 and over. The NLMMS has a total of 1,505 respondents and has a margin of error of -. Survey responses included telephone (mix of landline and cell phone) and web interviews. Latino Decisions fielded the survey in October 2016.

This unique survey was designed by an interdisciplinary team of health policy scholars and utilizes the Social Determinants of Health framework to gain a deeper knowledge of the New Mexican experience. Included in these themes was CAM utilization. The CAM battery included two questions:

I. In the past $\mathbf{1 2}$ months, did you seek care from any of the following:
a. Acupuncture.
b. Chiropractor
c. Curandero
d. Shaman
e. Spiritual Healer
f. Other

II. In the past 12 months, did you take any herbs and supplements including teas or oil(s)?

These two questions have been used in previous studies, including those cited in this paper (NHIS and NAWS). 


\section{Results}

The most commonly used CAM practices were chiropractor (11\%) and the "other" category (13\%). The "other" category was open ended, and responses included: reflexologists, homeopathic practitioner, hot springs, life coaches, massage therapists, oriental medicine practitioner, santero, priest, and yoga. Members of the LGBTQ community and respondents who listed "other ethnicity" were consistently the highest users of CAM across the different providers and service categories. The tables below provide a breakdown of those respondents who indicated they had used any CAM providers by socioeconomic and demographic characteristics (Table 2).

Utilization rates did not differ much between men and women or by marital status. There were some differences by age, however. Those 50 years and older reported a 20\% utilization of "other" sources of CAM compared to only $12 \%$ among those between the ages of $40-49,11 \%$ between the ages of $30-39$, and $4 \%$ among the youngest age group. Chiropractic and acupuncture use was highest among those with the highest levels of education and income and those with health insurance. These results are similar to McKenzie et al (2003) that find that the uninsured and those with an education level of high school or above are more likely to use CAM (Table 3).

\section{Affordable Services}

The question of whether CAM is more affordable than conventional healthcare has yet to be answered conclusively. The question may not be answerable when the data is looked at in aggregate. Looking at the practices that have definitive benefits (e.g. aromatherapy and acupuncture) and comparing those with the leading therapies offered by the traditional healthcare (anxiety and nausea respectively) specialists might yield the most useful information. Clearly if CAM therapies can be marketed as conclusively more affordable than more traditional therapies and they have risks that are less severe than those therapies (e.g. opioid dependence) then that could go a long way toward increasing the popularity, usage and acceptance of these therapies in the United States. CAM and historically disadvantaged groups are inextricably linked in their history and current context of being othered. For our purposes "othering" means to establish identity and superiority based on opposition to and from a dichotomous viewpoint that establishes the identity of the perpetuator as superior. Often this "othering" is based on fallacy. For example, Gale [26] uses the examples of osteopathy and homeopathy which are often perceived as culturally divergent from Western medicine, but are in fact practices native to the United States and Germany respectively (Table 4).

Table 2: Those reporting usage of CAM providers by Gender, Age, Sexuality \& Marital Status.

\begin{tabular}{|c|c|c|c|c|c|c|c|c|c|c|}
\hline & & \multicolumn{2}{|c|}{ Gender } & \multicolumn{4}{|c|}{ Age } & Sexuality & \multicolumn{2}{|c|}{ Marital Status } \\
\hline & Total & Men & Women & $18-29$ & $30-39$ & $40-49$ & $50+$ & LGBTQI & Married & Single \\
\hline Acupuncture & $60(5 \%)$ & $21(3 \%)$ & $40(6 \%)$ & $16(5 \%)$ & $12(7 \%)$ & $11(6 \%)$ & $19(3 \%)$ & $12(13 \%)$ & $27(4 \%)$ & $34(5 \%)$ \\
\hline Chiropractor & $153(11 \%)$ & $70(11 \%)$ & $82(12 \%)$ & $30(10 \%)$ & $28(17 \%)$ & $16(8 \%)$ & $75(12 \%)$ & $18(20 \%)$ & $83(13 \%)$ & $69(10 \%)$ \\
\hline Curandero & $23(2 \%)$ & $11(2 \%)$ & $10(3 \%)$ & $10(3 \%)$ & $4(3 \%)$ & $1(* \%)$ & $7(1 \%)$ & $7(7 \%)$ & $6(1 \%)$ & $17(2 \%)$ \\
\hline Shaman & $13(1 \%)$ & $4(1 \%)$ & $9(1 \%)$ & $5(2 \%)$ & - & $3(2 \%)$ & $6(1 \%)$ & $1(1 \%)$ & $1(* \%)$ & $12(2 \%)$ \\
\hline $\begin{array}{c}\text { Spiritual } \\
\text { Healer }\end{array}$ & $39(3 \%)$ & $14(2 \%)$ & $24(4 \%)$ & $5(1 \%)$ & $8(5 \%)$ & $6(3 \%)$ & $19(3 \%)$ & $5(6 \%)$ & $13(2 \%)$ & $25(4 \%)$ \\
\hline Other & $177(13 \%)$ & $99(16 \%)$ & $78(11 \%)$ & $12(4 \%)$ & $19(11 \%)$ & $22(12 \%)$ & $124(20 \%)$ & $5(6 \%)$ & $100(16 \%)$ & $77(11 \%)$ \\
\hline $\begin{array}{c}\text { Total } \\
\text { (weighted) }\end{array}$ & 1330 & 631 & 694 & 303 & 168 & 635 & 635 & 93 & 644 & 673 \\
\hline
\end{tabular}

Table 3: Those reporting usage of CAM providers by Education, Income, \& Health Insurance Status.

\begin{tabular}{|c|c|c|c|c|c|c|c|c|c|}
\hline & & \multicolumn{3}{|c|}{ Education } & \multicolumn{3}{c|}{ Income } & \multicolumn{2}{c|}{ Health Insurance } \\
\hline & Total & HS or Less & Some College & College Grad+ & $<\$ 40 k$ & $\$ \mathbf{4 0 k - 8 0 k}$ & $\$ 80 k+$ & Insured & Uninsured \\
\hline Acupuncture & $60(5 \%)$ & $10(3 \%)$ & $12(3 \%)$ & $38(6 \%)$ & $22(4 \%)$ & $17(4 \%)$ & $14(5 \%)$ & $60(5 \%)$ & $0(* \%)$ \\
\hline Chiropractor & $153(11 \%)$ & $22(7 \%)$ & $30(9 \%)$ & $101(16 \%)$ & $43(8 \%)$ & $49(13 \%)$ & $48(17 \%)$ & $147(12 \%)$ & $6(7 \%)$ \\
\hline Curandero & $23(2 \%)$ & $4(1 \%)$ & $6(2 \%)$ & $13(2 \%)$ & $10(2 \%)$ & $8(2 \%)$ & $5(2 \%)$ & $20(2 \%)$ & $3(4 \%)$ \\
\hline Shaman & $13(1 \%)$ & $5(1 \%)$ & $2(\%)$ & $7(1 \%)$ & $8(1 \%)$ & $5(1 \%)$ & $0(* \%)$ & $13(1 \%)$ & - \\
\hline $\begin{array}{c}\text { Spiritual } \\
\text { Healer }\end{array}$ & $39(3 \%)$ & $8(3 \%)$ & $10(3 \%)$ & $2(3 \%)$ & $21(4 \%)$ & $9(2 \%)$ & $6(2 \%)$ & $36(3 \%)$ & $2(3 \%)$ \\
\hline $\begin{array}{c}\text { Other } \\
\text { Total } \\
\text { (weighted) }\end{array}$ & $177(13 \%)$ & $33(10 \%)$ & $52(15 \%)$ & $91(14 \%)$ & $66(13 \%)$ & $48(13 \%)$ & $40(14 \%)$ & $168(13 \%)$ & $9(12 \%)$ \\
\hline
\end{tabular}

Citation: Dinallo A, Allison G, Juarez M (2017) Complementary and Alternative Medicine (CAM) Utilization Rates in New Mexico: Recommendations for Marketing and Mentorship between Professionals and Students. Int I Complement Alt Med 9(1): 00287. DOI: 10.15406/ijcam.2017.09.00287 
Table 4: Those reporting usage of CAM providers by Race, Ethnicity, \& Nativity Status.

\begin{tabular}{|c|c|c|c|c|c|c|c|}
\hline & & \multicolumn{7}{|c|}{ Race \& Ethnicity } & \multicolumn{2}{c|}{ Nativity } \\
\hline & Total & White & Hispanic & Native American & *Other Ethnicity & US Born & Foreign Born \\
\hline Acupuncture & $60(5 \%)$ & $26(5 \%)$ & $32(5 \%)$ & $*$ & $2(15 \%)$ & $56(5 \%)$ & $5(5 \%)$ \\
\hline Chiropractor & $153(11 \%)$ & $79(14 \%)$ & $66(10 \%)$ & $6(6 \%)$ & $2(13 \%)$ & $137(11 \%)$ & $16(16 \%)$ \\
\hline Curandero & $23(2 \%)$ & $4(1 \%)$ & $18(3 \%)$ & $1(1 \%)$ & - & $20(2 \%)$ & $3(3 \%)$ \\
\hline Shaman & $13(1 \%)$ & $2(* \%)$ & $4(1 \%)$ & $7(7 \%)$ & - & $11(1 \%)$ & $2(2 \%)$ \\
\hline Spiritual Healer & $39(3 \%)$ & $9(2 \%)$ & $20(3 \%)$ & $9(9 \%)$ & $1(4 \%)$ & $36(3 \%)$ & $2(2 \%)$ \\
\hline Other & $177(13 \%)$ & $94(16 \%)$ & $69(11 \%)$ & $12(12 \%)$ & $2(10 \%)$ & $172(14 \%)$ & $5(6 \%)$ \\
\hline Total (weighted) & 1330 & 581 & 628 & 104 & 17 & 1229 & 98 \\
\hline
\end{tabular}

Whites, those in the "other ethnicity" category, and the foreignborn have the highest use of chiropractors across racial and nativity groups. Native Americans had the highest usage rates for both spiritual healers (9\%) and shamans (7\%) compared to other groups. All groups except the foreign-born reported above $10 \%$ usage for other sources of CAM. Again, similar to McKenzie et al's (2003) findings, that the type of CAM used varied based on ethnicity, with their study finding that whites $(13 \%)$ were more likely to use chiropractors while Native Americans (29\%) and Asians (26\%) were more likely to use herbal medicine. Their study also found that Native Americans more likely to use traditional healers $(7 \%)$ than any other racial or ethnic group, similar to our results (McKenzie et al. 2003).

\section{Marketing Strategies}

One can assume that this gap of utilization may be due to access or a lack of education around alterative and complement medical services. When it comes to marketing, cultural congruence is an avenue to explore. For example, marketing CAM based on some of its linkages to folk, indigenous, and Eastern traditions would likely endear it to groups who have cultural connections or interests and/or are open to the practices of those traditions. In contrast, those links would likely repel those who reject and/or are complicit with messages of Western superiority when it comes to medicine and technology. This argument suggests a direct marketing approach based on differentiated group orientations as opposed to a mass marketing strategy.

Mass marketing strategies have proven effective for reaching the masses, but they are often less effective for reaching targeted groups. Specifically, underserved groups where language and cultural barriers represent obstacles to health communication [27]. Studies have shown similar issues regarding the marketing to and the recruitment of socio-economically disadvantaged populations [28]. Underserved communities have a long history of being neglected when it comes to marketing efforts, and therefore targeted marketing has the potential to attract members of those communities. In particular, targeted print material has proven to be a more effective strategy for reaching underserved communities. These types of materials can be constructed in a way that is culturally relevant and placed in locations that are high traffic and easy to access such as grocery stores, community centers, community events, and churches. When marketing it is necessary to project the socio-economic climate of healthcare services.

\section{Mentorship}

In NM older adults tend to use CAM more than younger populations. Those $50+$ reported a $20 \%$ utilization of "other" sources of CAM compared to only $12 \%$ among those between $40-49,11 \% 30-39$, and $4 \%$ among the youngest age group. Given the low utilization rates across CAM disciplines for youth in New Mexico CAM education should ideally be focused on younger populations through mentorship opportunities. Mentorship allows one to "identify and seek to learn from, and often emulate" and develop problem solving skills, decision making, interpersonal abilities through personal guidance [29]. Some of the functions of a mentor relationship include training through formal and informal dialog, providing intrapersonal support, and encouragement to meet personal goals [30].

Mentorship has demonstrated a longstanding ability to improve attitudes toward school, increase reading, and enhance academic preparation in youth relationships [31-33]. Literature suggests that the greatest scholastic improvements occur when mentees spend ample time together [34]. While mentorship programs are acclaimed for increasing scholastic productivity, additional studies demonstrate that peer mentorship creates networks of emotional support for both students who are mentors and mentees [35-37]. More recently, mentorship strategies are being use to increase CAM therapy awareness, and improve behavioral health in school settings.

The Holistic Life Foundation (HLF) is a non-profit that serves 14 schools in underserved communities in the Baltimore area by offering students meditation, yoga, and self-care practices. The foundation supports schools with a mindfulness room that students can use before or after school, trainings and mentorship opportunities across college students, high schoolers, and middle schools. The program has internships, trainings for volunteers, and workshops that serves 4,500 students per week. HLF mentorship model has mitigated suspension rates and increased other measures of behavioral health including; self-regulation, self-esteem, and breathing awareness [38]. 
The HLF foundation is an example of ways that evidence based CAM services like yoga and meditation can be integrated into school settings to benefit student well-being and increase exposure to CAM therapies.

\section{Contextual Considerations}

CAM represents a diverse set of healing modalities that each originates from a unique culture, geography, and worldview. In the NLMMS survey open ended responses demonstrated a broad spectrum of usages ranging from Oriental Medicine, yoga to Santeria (Mexican artisan religious craftmaking). Oriental Medicine originates from China and includes practices like acupuncture, tai chi and herbs. Yoga has roots in Hinduism, Buddhism, and Jainism and includes movement and breath practices that are enmeshed within Indian culture. Santeria comes from traditional folk medicine (curanderismo) and has roots in many indigenous and Mayan practices that include cupping, ritual and herbs as forms of healing.

These historical practices have assimilated into western culture where Americans are spending $\$ 14.7$ billion on complementary practitioners and $\$ 12.8$ billion on supplements. Yet, the assimilation of these practices is a double edge sword that requires an intersecting lens that interrogates power, history and oppression. On one side, old world medicinal practices that have effectivity should be shared with all groups. This can be achieved through targeted marketing and educational strategies like mentorship between conventional and CAM professionals. Yet, these efforts must contextualize the historical and cultural worldview of each modality with cultural competence and respect. Many CAM practices were destroyed in efforts to support the age of reason and dominant practices of conventional medicine that was intertwined into patriarchy.

Today, the cultural appropriation of spiritual healing for Indigenous populations is a struggle for many groups who aim to share healing traditions. In some cases, Sacred ceremony has been exposed in disrespectful ways [39] and is tied to language loss/ gesutural changes [40]. Traditional complementary and alternative medicinal practice must be developed in collaboration with key cultural stakeholders. Efforts to market CAM and create mentorship programs should adopt indigenous frameworks for research, education, and collaboration that aim to foster respect and cultural humility. Mentorship program can be developed between providers and between high school and middle school students [41-48].

\section{Conclusion}

Authors used New Mexico as the site of our case study given its status as a majority-minority state $(46.4 \%$ Hispanic, $8.8 \%$ Native American) and history of colonization and cultural appropriation. The most commonly used CAM practices were chiropractor $(11 \%)$ and the "other" category (13\%). The "other" category was open ended, and responses included: reflexologists, homeopath practitioner, hot springs, life coaches, massage therapists, oriental medicine practitioner, santero, priest, and yoga. Utilization rates did not differ much between men and women or by marital status. There were some differences by age, however. Those age 50 and above reported a $20 \%$ utilization of "other" sources of CAM compared to only $12 \%$ among those between the ages of $40-49,11 \% 30-39 \&$ and $4 \%$ among the youngest age group. Chiropractic and acupuncture use was highest among those with the highest levels of education and income and those with health insurance. To explore local engagement applications in the state of New Mexico, we suggest that health providers should use targeted marketing strategies, develop leadership trainings that bridge health paradigms.

\section{Conflicat of Interest}

None.

\section{References}

1. Chao MT, Wade C, Kronenberg F (2008) Disclosure of complementary and alternative medicine to conventional medical providers: variation by race/ethnicity and type of CAM. J Natl Med Assoc 100(11): 1341-1349.

2. Pal SK (2002) Complementary and alternative medicine: an overview. Current Science-Bangalore 82(5): 518-524.

3. YuanY CS, Bieber EJ (2003) Textbook of complementary and alternative medicine. Partenon Publishing Group, New York, USA.

4. http://www.mayoclinic.org/tests-procedures/complementaryalternative-medicine/basics/definition/prc-20021745

5. Hsiao AF, Wong MD, Goldstein MS, Yu HJ, Andersen RM, et al. (2006) Variation in complementary and alternative medicine (CAM) use across racial/ethnic groups and the development of ethnic-specific measures of CAM use. J Altern Complement Med 12(3): 281-290.

6. Bausell RB, Lee WL, Berman BM (2001) Demographic and healthrelated correlates of visits to complementary and alternative medical providers. Med Care 39(2): 190-196.

7. Najm W, Reinsch S, Hoehler F, Tobis J (2003) Use of complementary and alternative medicine among the ethnic elderly. Altern Ther Health Med 9(3): 50-57.

8. Ernst E (2000) Assessing the evidence base for CAM. In: Kelner \& Wellman (Eds.), Complementary and Alternative Medicine: Challenge and Change, Routledge Press, New York, USA, pp. 165172.

9. Nahin RL, Barnes PM, Stussman BJ (2016) Expenditures on complementary health approaches: United States, 2012. Natl Health Stat Report 95: 1-11.

10. Barnes PM, Powell-Griner E, McFann K, Nahin RL (2004) Complementary and alternative medicine use among adults: United States, 2002. Adv Data (343): 1-19.

11. Clarke TC, Black LI, Stussman BJ, Barnes PM, Nahin RL (2015) Trends in the use of complementary health approaches among adults: United States, 2002-2012. Natl Health Stat Report 79: 1-16.

12. Ni H, Simile C, Hardy AM (2002) Utilization of complementary and alternative medicine by United States adults: results from the 1999 national health interview survey. Med Care 40(4): 353-358.

13. Jamieson S (2004) Likert scales: How to (ab) use them. Med Educ 38(12): 1217-1218. 
14. Ware JE, Sherbourne CD (1992) The MOS 36-item short-form health survey (SF-36): I. Conceptual framework and item selection. Med Care 3(6): 473-483.

15. John PJ, Sharma N, Sharma CM, Kankane A (2007) Effectiveness of yoga therapy in the treatment of migraine without aura: A randomized controlled trial. Headache 47(5): 654-661.

16. Smith BW, Dalen J, Wiggins KT, Christopher PJ, Bernard JF, et al. (2008) Who is willing to use complementary and alternative medicine? Explore (NY) 4(6): 359-367.

17. Musgrave CF, Allen CE, Allen GJ (2002) Spirituality and health for women of color. Am J Public Health 92(4): 557-560.

18. Syed ST, Gerber BS, Sharp LK (2013) Traveling towards disease: Transportation barriers to health care access. J Community Health 38(5): 976-993

19. Farr M, Cressey P (2015) Understanding staff perspectives of quality in practice in healthcare. BMC Health Serv Res 15(1): 1-11.

20. Trotter RT, Chavira JA (2011) Curanderismo: Mexican American folk healing. Athens, University of Georgia Press, Georgia, USA.

21. Robinson A, McGrail, MR (2004) Disclosure of CAM use to medical practitioners: a review of qualitative and quantitative studies. Complement Ther Med 12(2): 90-98.

22. Tomedi LE, Padilla JL (2013) Health inequities by sexual orientation in New Mexico, 2005-2013. New Mexico Department of Health, USA.

23. https://nmhealth.org/publication/view/report/2045/

24. Portes A, MacLeod D (1996) Educational progress of children of immigrants: The roles of class, ethnicity, and school context. Sociology of Education 69(4): 255-275.

25. Mondragón JB, Stapleton ES (2005) Public education in New Mexico. Albuqueruqe, UNM Press, New Mexico, USA.

26. Gale N (2014) The sociology of traditional, complementary and alternative medicine. Sociol Compass 8(6): 805-822.

27. Powers DE, Stansfield CW, Educational Testing Service, Princeton N (1983) The test of spoken english as a measure of communicative ability in the health professions: Validation and standard setting. TOEFL Program Office, Educational Testing Service, Princeton, NJ USA.

28. Harkins C, Shaw R, Gillies M, Sloan H, MacIntyre K, et al. (2010) Overcoming barriers to engaging socio-economically disadvantaged populations in CHD primary prevention: A qualitative study. BMC Public Health 10(1): 1-7.

29. Tait J (2003) What is mentorship? Can Vet J 44(9): 758-760.

30. Singh DK, Stoloff DL (2003) Mentoring faculty of color: Essays on professional development and advancement in colleges and universities. Jefferson, McFarland \& Company, Inc, North Carolina, USA.

31. Eisenberg T, Fresko B, Carmeli M (1983) A follow-up study of disadvantaged children two years after being tutored. The Journal of Educational Research 76(5): 302-306.
32. Eisenberg DM, Kessler RC, Van Rompay MI, Kaptchuk TJ, Wilkey SA, et al. (2001) Perceptions about complementary therapies relative to conventional therapies among adults who use both: Results from a national survey. Ann Intern Med 135(5): 344-351.

33. Goldner L, Mayseless O (2009) The quality of mentoring relationships and mentoring success. J Youth Adolescence 38(10): 1339-1350.

34. Grossman JB, Rhodes JE (2002) The test of time: Predictors and effects of duration in youth mentoring relationships. Am J Community Psychol 30(2): 199-219.

35. Gettings PE, Wilson SR (2014) Examining commitment and relational maintenance in formal youth mentoring relationships. Journal of Social and Personal Relationships 31: 1089-1115.

36. Karcher MJ (2005) The effects of developmental mentoring and high school mentors' attendance on their younger mentees' selfesteem, social skills, and connectedness. Psychology in the Schools 42(1): 65-77.

37. Dubois DL, Neville HA (1997) Youth mentoring: Investigation of relationship characteristics and perceived benefits. Journal of Community Psychology 25(3): 227-234.

38. http://hlfinc.org/programs-services/omega-institute training/

39. Joralemon D (1990) The selling of the shaman and the problem of informant legitimacy. Journal of Anthropological Research 46(2): 105-118

40. Wilcox S (2012) Gesture and language, gesture as language, language as gesture: Comments on Loehr and Fais et al. Laboratory Phonology 3(1): 125-131.

41. Robertson A, Minkler M (1994) New health promotion movement: a critical examination. Health Educ Q 21(3): 295-312.

42. Fisher S (1991) A discourse of the social: medical talk/power talk/ oppositional talk? Discourse \& Society 2(2): 157-182.

43. Herman CJ, Allen P, Hunt WC, Prasad A, Brady TJ (2004) Use of complementary therapies among primary care clinic patients with arthritis. Prev Chronic Dis 1(4): A12.

44. Lupton D (1997) Foucault and the medicalisation critique. In A Petersen \& R Bunton (Eds.), Foucault, health and medicine. Routledge Press, New York, USA, pp. 94-110.

45. Mackenzie ER1, Taylor L, Bloom BS, Hufford DJ, Johnson JC (2003) Ethnic minority use of complementary and alternative medicine (CAM): A national probability survey of CAM utilizers. Altern Ther Health Med 9(4): 50-56.

46. Måseide P (1991) Possibly abusive, often benign, and always necessary: On power and domination in medical practice. Sociology of Health \& Illness 13(4): 545-561.

47. http://mayoclinichealthsystem.org/medical-services

48. http://www.cdc.gov/nchs/data/series/sr_10/sr10_260.pdf 